\title{
Carcass Washing as an Alternative to Trimming - Is It Possible to Use Carcass Washing as an Alternative to Trimming in Commercial Broiler Slaughterhouses in Brazil?
}

\section{mAuthor(s)}

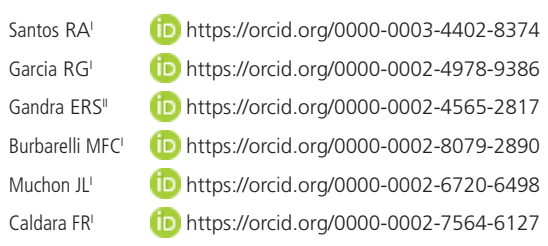

Faculdade de Ciências Agrárias - FCA Universidade Federal da Grande Dourados - UFGD - Dourados - MS - Brasil.

Instituto de Estudos do Trópico Úmido - IETU Universidade Federal do Sul e Sudeste do Pará UNIFESSPA Xinguara, PA - Brasil.

\section{-Mail Address}

Corresponding author e-mail address Maria Fernanda de Castro Burbarelli Faculdade de Ciências Agrárias - FCA Universidade Federal da Grande Dourados

- UFGD - Rodovia Dourados/Itahum, Km

12 - Unidade II Dourados - MS Brasil | Caixa Postal: 364 | CEP:79.804-970

Phone: +5519 99947-7777

Email: fariakita@gmail.com

\section{- Keywords}

Condemnation, poultry, sanitation, slaughter, trimming.

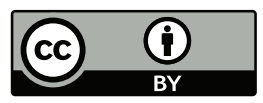

Submitted: 23/October/2019

Approved: 17/March/2020

\section{ABSTRACT}

This study aimed to evaluate visual contamination rates of carcasses of broilers slaughtered in establishments supervised by the Federal Inspection Service (SIF) and efficiency of carcass washing in replacement of trimming. The work was divided into three parts: analysis of partial and total carcass condemnation by contamination in hot (October to March) and cold (April to September) periods; evaluation of microbiological contamination before and after washing 800 carcasses (400 that did not go through washing $\times 400$ that went through washing); and carcass washing test. For the test, twenty carcasses were evaluated in five treatments: carcasses without contamination - before washing; carcasses without contamination - after washing; contaminated carcasses - before washing and before trimming; contaminated carcasses - after washing; contaminated carcasses after trimming. Hot and cold periods obtained a similar number and weight of slaughtered chickens. There were no differences regarding condemnation by contamination. Periods of the year did not influence the average weight of the birds slaughtered in the state of Mato Grosso do Sul. Carcass washing in the slaughter line was effective in reducing total bacterial contamination, E. coli, and enterobacteria. There is a similarity in the reduction of condemnations by contamination, evidencing that the uniformity of production systems. Although it is not yet a reality in Brazilian slaughterhouses, the washing procedure can be considered a safe replacement for trimming.

\section{INTRODUCTION}

The modern broiler slaughtering process is a complex, fast, and highly automated process of removing bacteria-free meat from two contaminated surfaces: feathers and the gastrointestinal tract. It must prevent contamination of carcasses, which represents a great challenge (Milios et al., 2014a; Jacxsens et al., 2015; Zweifel et al., 2015; Evers et al., 2017).

In order to minimize contamination and its possible effects, selfcontrol plans are prepared, monitored daily by companies, and verified by the Brazilian Federal Inspection Service (SIF). These plans include the Operational Health Procedures (OHP), the Standard Operating Hygiene Procedure (SOHP), and the Hazard Analysis and Critical Control Points (HACCP) (Brazil, 1998; Brazil, 2006).

Pathogenic microorganisms may enter the slaughterhouse plant along with the birds. Some processing steps, such as scalding, may reduce bacterial load. Other stages, such as plucking and evisceration, may cause carcass contamination (Giombelli et al., 2015).

The most traditional form used to promote visible decontamination of small areas is cutting. This process, known as trimming in the meat processing industry, is common in Brazil (Brizio et al., 2015) and in 
countries such as Australia (Brashears and Chaves, 2017). It aims to reduce the load of bacteria in visibly contaminated sites, but cannot be used on whole carcasses (Brashears \& Chaves, 2017).

Although efficient in removing visible contamination, trimming requires extra handling of carcasses, increasing the possibility of cross-contamination (Giombelli et al., 2015) and of causing financial losses due to extra labor and condemnation of carcasses and other parts (Chen et al., 2014; Lehner et al., 2014; Stefani et al., 2014; Pawar et al., 2016; Sohaib et al., 2016).

An alternative form of decontamination is carcass washing (Lehner et al., 2014; Milios et al., 2014b; Giombelli et al., 2015; Brashears \& Chaves, 2017). It is considered controversial by some Federal Agricultural Auditors responsible for the Federal Inspection Service (SIF), who are still reluctant to approve it (Stefani et al., 2014).

Nevertheless, this system has been gaining ground and is routinely used in processing plants. It has been shown to be effective in removing visible physical contaminants such as soil, feathers, gastrointestinal contamination, and other waste, as well as improving the microbiological quality of carcasses (Lehner et al., 2014; Giombelli et al., 2015).

The washing system differs from the carcass shower before the pre-cooling system, as recommended by the Ordinance no. 210/98 (Brazil, 1998), because it is used for the removal of apparent contamination of carcasses. It is performed at a different location in the plant and uses pressurized water jets. The United States (USA) allows the use of chemical decontaminants to be added to the wash water. It is a standard procedure (Chen et al., 2014; Belluco et al., 2016; Sohaib et al., 2016; Brashears \& Chaves, 2017). In contrast, Brazilian law allows the use of a maximum of five ppm of chlorine in industrial water (Brasil, 1998).

The objectives of this work are to: 1) evaluate the visual contamination rates of carcasses and carcass parts slaughtered in establishments supervised by the Federal Inspection Service (SIF), 2) determine the microbiological contamination of carcasses before and after carcass washing under pressurized water, and 3) compare the efficiency of broiler carcass decontamination methods.

\section{MATERIAL AND METHODS}

\section{Slaughterhouses and slaughter process}

The trial was conducted in commercial slaughterhouses supervised by the Federal Inspection
Service (SIF) located in the state of Mato Grosso do Sul. The slaughtering process was performed following the commercial slaughtering flow chart: reception of birds, rest, hanging, stunning, bleeding, scalding, and plucking in dirty and intermediate areas. Post-plucking washing separates the dirty area from the clean area. The clean area comprises pre-inspection, foot trimming, re-hanging, cloaca extraction, abdominal cutting, eventration, postmortem inspection, gutting, lung and trachea removal, head/neck removal, carcass review, final washing, pre-cooling of carcasses, and primary packaging and secondary packaging.

In the slaughterhouses evaluated during the slaughter process, only one has not yet adhered to the carcass washing system. However, all still use trimming as a form of decontamination.

\section{Partial and total carcass condemnation by contamination}

At this first stage, the reports of monthly slaughter data and partial and total carcass condemnations of the five establishments supervised by the Federal Inspection Service that slaughter birds in the state of Mato Grosso do Sul (A, B, C, D, and E) were analyzed between August 2016 and August 2017, according to data from the Federal Inspection Service Management Information System (SIGSIF). Data from condemnations by contamination were analyzed by calculating the proportion (\%) between total birds slaughtered in cold (April to September) and hot (October to March) periods. Each month of the period is a replication. Thus, monthly averages were generated per period (cold or hot) for condemnations by partial contamination and condemnation by total contamination.

\section{Microbiological contamination before and after carcass washing}

After prior authorization by the Animal Products Inspection Service of the Federal Superintendence of Agriculture of the State of Mato Grosso do Sul (SIPOA/SFA/MS), with the objective of analyzing the microbial population before and after carcass washing with pressurized drinking water, slaughterhouse A installed a wash cabin with eight spray nozzles after the eviscerator machine: four chest-directed and four back-directed nozzles with pressurized water (5.0 kgf/ $\mathrm{cm}^{2}$ ) and a minimum water volume of $150 \mathrm{ml} /$ carcass directed to the outer surface of the carcasses.

At this establishment, after the evisceration stage, the viscera were transferred to a noria separate from 
the carcasses, allowing water to spray only on the outer surface of the carcasses. Drinking water standards were in accordance with national and European Union legislation. The sample collection was performed according to the routine of the establishment and the Official Service (Brasil, 1998).

To compare the microbiological contamination of carcasses before the washing with those after the cabin, 800 carcasses were randomly collected in October 2016, 400 carcasses before and 400 carcasses after the washing cabin. The carcasses were subjected to microbiological analysis for detection and quantification of the following microorganisms: enterobacteria populations (Log CFU/g) (AFNOR, 1997), total bacterial count (Log CFU/g), and E. coli (Log CFU/g) (AOAC, 1991).

To carry out the test, the company set a limit of up to $12 \%$ of carcasses arriving with gastrointestinal contamination visually detected before the installed washing cabin, considering that washing could not compensate for equipment failures at the evisceration stage (cloaca extraction and abdominal section).

\section{Decontamination method efficiency - experi- mental assay}

In order to study the effects of the carcass washing or trimming decontamination methods, carcasses of broilers were collected in slaughterhouse A. Its slaughtering capacity is up to 160,000 birds per day. The average processing speed of the slaughter line is up to 10,200 birds/h, and the evisceration system is automated. Samples were randomly collected from 25 lots belonging to 16 producers with a slight degree of external contamination by feed and/or visible excreta and without visible contamination, classified according to the five treatments with twenty samples by treatment:

- Carcasses without contamination - before washing;

- Carcasses without contamination - after washing;

- Contaminated carcasses - before washing and before trimming;

- Contaminated carcasses - after washing;

- Contaminated carcasses - after trimming.

During the slaughtering process, for monitoring the carcass washing efficiency, slaughterhouse $A$ evaluates the washing pressure before the critical control point (CCP) every six hours, and the water flow is checked every 12 hours. The measurement of the number of contaminated carcasses reaching the washing is a sanitary operating procedure (SOP) and must be a maximum of $12 \%$. Other parameters are monitored, such as the direction of the water jets, the integrity of the spray nozzles and water pressure, which must be at least $2 \mathrm{~kg} / \mathrm{cm}^{2}$ and its flow should be higher or equal to $300 \mathrm{ml} /$ carcass.

The carcasses were individually collected and packed in sterile polyethylene bags, identified and sent refrigerated in polypropylene boxes to the Company $A$ self-control laboratory.

The total mesophyll count (CFU/g/ml) was performed by the AOAC 990.12 201 (Petrifilm Aerobic Count Plate and Petrifilm Aerobic Count Plate Rapid) depth technique (AOAC, 1990). For the count of $E$. coli (CFU/g/ml), the depth counting technique AOAC 990.12201 (Petrifilm) (AOAC, 1990) was used, following the $3 \mathrm{M}$ interpretation source guide (AOAC, 2015).

The analysis of Salmonella spp. was conducted by qualitative determination and the presence or absence technique, according to the ISO 6579-2002 (ISO, 2002).

\section{Statistical analyses}

The evaluation of the results of partial and total carcass condemnations by contamination, microbiological contamination before and after carcass washing, and experimental carcass washing and trimming assay were obtained using SAS (Statistical Analysis System, version 9.3). The normality of residues and the homogeneity of variances were verified by the PROC UNIVARIATE package (SAS, 2012).

After the normality test, the results were analyzed by PROC MIXED, adopting a significance level of $5 \%$, according to the following models:

For the analysis of the first experiment:

$Y_{i}=\mu+E_{j}+e_{i}$

For analysis of the second experiment:

$\mathrm{Y}_{\mathrm{i}}=\mu+\mathrm{Sl}_{\mathrm{i}}+\mathrm{e}_{\mathrm{i}}$

For analysis of the third experiment:

$\mathrm{Y}_{\mathrm{i}}=\mu+\mathrm{L}_{\mathrm{i}}+\mathrm{e}_{\mathrm{i}}$

Where: $Y_{i}=$ dependent variable, $\mu=$ general mean, $E_{i}=$ random season effect ( $j=1$ to 4$) ; S I_{i}=$ washing system effect ( $i=1$ to 2 ); $L_{i}=$ carcass washing effect ( $i=1$ to 5$)$. The degrees of freedom were corrected by $\operatorname{DDFM}=\mathrm{kr}$. The data obtained were submitted to analysis of variance using the PROC MIXED command of SAS (SAS, 2012), adopting a significance level of $5 \%$. 


\section{RESULTS AND DISCUSSION}

\section{Analysis of data behaviour of partial and total carcass condemnation by contamination}

There were no effects on the total number of birds slaughtered and their average weight ( $p>0.05)$ in the cold and hot periods in 2016 (Table 1). The average weight of birds slaughtered was $2.35 \mathrm{~kg} / \mathrm{bird}$, with an average weight of 2.38 and $2.32 \mathrm{~kg} /$ bird slaughtered in the cold and hot periods of the year, respectively (Table 1).

Table 1 - Total birds slaughtered and their average weight per slaughterhouse and periods of the year (cold versus hot).

\begin{tabular}{lcccc}
\hline \multirow{2}{*}{ Slaughterhouse } & \multicolumn{2}{c}{ Total birds slaughtered } & \multicolumn{2}{c}{ Average weight $(\mathrm{kg})$} \\
\cline { 2 - 5 } & Hot* $^{*}$ & Cold $^{*}$ & Hot & Cold \\
\hline A & $20,532,017$ & $19,657,113$ & 2.77 & 2.88 \\
B & $17,844,539$ & $18,967,515$ & 2.42 & 2.46 \\
C & $13,499,729$ & $15,275,437$ & 1.10 & 1.08 \\
D & $26,044,715$ & $26,800,952$ & 2.73 & 2.83 \\
E & $5,993,356$ & $5,530,075$ & 2.56 & 2.64 \\
\hline MSE $^{1}$ & \multicolumn{2}{c}{0.950} & \multicolumn{2}{c}{0.381} \\
\hline P2 $^{2} 0.671$ & \multicolumn{2}{c}{0.541} \\
\hline
\end{tabular}

*Hot: October to March; Cold: April to September; MSE' mean standard error; ${ }^{2 S i g n i-}$ ficance of $p<0.05$.

In addition, according to this evaluation, slaughterhouse $D$ showed a greater regularity of the number of birds slaughtered, without presenting sharp reductions in slaughter between seasons. The average weight of broilers slaughtered in slaughterhouse $\mathrm{C}$ $(1.60 \mathrm{~kg} / \mathrm{bird})$ is because their activity is related to the production of griller chickens for Middle Eastern countries. Slaughterhouses A, B, C, and E focus their production on the production of frozen chicken cuts in natura, and the average weight of chicken correlated directly with the weight of the cuts, which meets the demand of buyers.

The difference observed between the number of birds slaughtered and their average weight follows the behavior of the consumer market and the contracts of each industry. The choice of the location of processing agro-industries is considered a strategic action of major importance for the development of the production chain. Companies are installed in major producing regions of soybean and corn crops (Rodrigues et al., 2015).

Regarding partial and total condemnations by contamination (Table 2), no effects ( $p>0.05$ ) were observed for the evaluated periods of the year (hot and cold), reflecting the homogeneity and standardization of the broiler meat production process (Silva et al., 2014). Climate factors were sufficiently controlled during poultry breeding, allowing the average slaughter weight to meet the performance standard of the equipment used at the evisceration stage (Flanders \& Gillespie, 2016).

Table 2 - Means of partial (\%) and total (\%) condemnation by contamination of slaughtered chicken carcasses in the five slaughterhouses evaluated by period of the year (hot versus cold) from August 2016 to August 2017.

\begin{tabular}{lcccc}
\hline \multirow{2}{*}{ Slaughterhouse } & \multicolumn{2}{c}{ Partial contamination (\%) } & \multicolumn{2}{c}{ Total contamination (\%) } \\
\cline { 2 - 5 } Hot & Cold & Hot & Cold \\
\hline A & 0.36 & 0.41 & 6.15 & 5.87 \\
B & 0.04 & 0.01 & 0.44 & 0.38 \\
C & 0.17 & 0.13 & 5.14 & 1.88 \\
D & 0.25 & 0.42 & 2.49 & 1.46 \\
E & 0.04 & 0.05 & 1.16 & 1.54 \\
\hline MSE $^{1}$ & \multicolumn{3}{c}{0.020} & \multicolumn{3}{c}{0.450} \\
\hline P $^{2}$ & 0.464 & \multicolumn{3}{c}{0.358} \\
\hline
\end{tabular}

MSE'1 mean standard error; ${ }^{2}$ Significance of $p<0.05$.

\section{Evaluation of reduction of microbiological contamination before and after carcass washing}

Carcass washing as a reducing factor of microbiological contamination (Table 3 ) was effective $(p<0.0001)$, causing a reduction of the total bacterial count $\left(\log _{10} \mathrm{CFU} / \mathrm{g}\right)$ of E. coli $\left(\log _{10} \mathrm{CFU} / \mathrm{g}\right)$ and enterobacteria ( $\log _{10}$ CFU/g) (Table 3 ) by $24.52 \%$, $30.26 \%$, and $28.71 \%$, respectively.

Table 3 - Microbiological contamination before and after carcass washing.

\begin{tabular}{lcccc}
\hline \multirow{2}{*}{ Count $\left(\log _{10}\right.$ CFU/g) } & \multicolumn{2}{c}{ Washing } & \multirow{2}{*}{ MSE1 } & \multirow{2}{*}{ P2 $^{2}$} \\
\cline { 2 - 3 } & Before & After & & \\
\hline Total bacteria & 4.84 & 3.57 & 0.04 & $<0.0001$ \\
Enterobacteria & 4.01 & 2.77 & 0.04 & $<0.0001$ \\
Escherichia coli & 3.35 & 2.25 & 0.03 & $<0.0001$ \\
\hline
\end{tabular}

MSE'1 mean standard error; ${ }^{2}$ Significance of $p<0.05$.

The meta-analysis study by Belluco et al. (2016) also demonstrated a reduction of microbial load of $E$. coli and enterobacteria after carcass washing. Isolan et al., (2019) also observed a reduction of microbial load of Salmonella after carcass washing. However, Giombelli et al. (2015) did not observe a reduction of E.coli after carcass decontamination in five different refrigeration plants. Possibly, such divergence is due to the microbial load present in the carcass, even with only one visible contamination point.

\section{Decontamination method efficiency - experimental assay}

The results showed no differences between decontamination methods ( $p>0.05$ ) regarding mesophyll count $\left(\log _{10}\right)$ and E. coli $\left(\log _{10}\right)$ count for carcasses with small areas of apparent contamination before and after carcass washing and trimming (Table 4). 
Table 4 - Medians of mesophyll $\left(\log _{10}\right)$ and E. coli $\left(\log _{10}\right)$ counts in broiler carcasses before and after carcass washing and trimming.

\begin{tabular}{|c|c|c|c|c|c|c|c|}
\hline \multirow{2}{*}{ Count ( $\log _{10}$ CFU/g) } & \multicolumn{2}{|c|}{ Not contaminated } & \multicolumn{3}{|c|}{ Contaminated } & \multirow{2}{*}{ MSE'1 } & \multirow{2}{*}{$P^{*}$} \\
\hline & Before & After ${ }^{1} \mathrm{CWS}$ & Before & After ${ }^{1} \mathrm{CWS}$ & After ${ }^{2} \mathrm{~T}$ & & \\
\hline Mesophylls & 4.171 & 4.174 & 4.105 & 4.042 & 4.042 & 0.047 & 0.868 \\
\hline E. coli & 3.086 & 3.225 & 3.162 & 3.120 & 3.120 & 0.054 & 0.938 \\
\hline
\end{tabular}

${ }^{1} \mathrm{CWS}=$ carcass washing system; ${ }^{2 T}=$ trimming; $\mathrm{MSE}^{3}=$ mean standard error; ${ }^{*}$ Significance of $p<0.05$.

As the presence of Salmonella spp. was not detected in the evaluated carcasses, it was not possible to evaluate the microbial load of the carcasses for this parameter, relating it to the systems evaluated.

Possibly, the microbiological load in the points identified in the carcasses was low. Its removal or not did not change the total carcass contamination. Thus, it was not possible to observe significant differences before and after decontamination by carcass trimming or washing. Several authors have claimed that these agents are reduced after decontamination practices (Milios et al., 2014a; Stefani et al., 2014; Giombelli et al., 2015; Belluco et al., 2016; Seliwiorstow et al., 2016; Brashears \& Chaves, 2017), highlighting its importance to commercial slaughtering procedures. Other factors may be correlated to these results, such as microbiological residence time and the pressure and volume of water used in the cabins evaluated by the researchers.

Although the legislation allows using carcass washing as an aid in reducing visible contamination (Brazil, 2011), the details of water pressure, volume, and system location (especially if before or after SIF inspection lines), among other details, are unregulated, which makes standardization of results difficult.

An important aspect to be considered is that, although there is a carcass washing system in the evaluated slaughterhouses, it is installed after the SIF inspection lines and the carcasses have previously undergone decontamination by trimming. In daily practice, there is an overlap of decontamination methods (carcass washing and trimming) after the carcass review step, which may be beneficial for the sanitary quality of the final products. There is concern about the possibility of contamination diffusion and its expansion to larger carcass areas after washing (Belluco et al., 2016). This possibility was not found in the present study since there were no differences ( $p>0.05$ ) between treatments, including for carcasses without contamination.

\section{CONCLUSION}

The hot and cold periods of the year did not influence the average weight of birds slaughtered in the state of
Mato Grosso do Sul between August 2016 and August 2017, evidencing that the breeding systems minimized the climatic effects. Moreover, in both periods, there is a similarity in the reduction of condemnations by contamination, evidencing that the uniformity of production systems and the inspection by the Federal Inspection Service are efficient. Carcass washing in the slaughter line was effective in reducing total bacterial contamination, E. coli, and enterobacteria. Its use is possible in replacement for trimming.

\section{ETHICS AND BIOSAFETY COMMITTEE}

The work was conducted in commercial slaughterhouses supervised by the Federal Inspection Service (SIF), located in the state of Mato Grosso do Sul. The BRF/SIF 18 Ethics Committee on Animal Use approved the project under no. 076/18/14.

\section{AUTHORS' CONTRIBUTIONS}

All authors contributed equally to the design and writing of the manuscript. All authors critically reviewed the manuscript and approved the final version.

\section{ACKNOWLEDGMENTS}

The authors thank CAPES for granting scholarships for postgraduate programs and conducting research projects.

\section{CONFLICT OF INTERESTS}

The authors declare no conflict of interest.

\section{REFERENCES}

AFNOR. 3M TM Petrifilm ${ }^{\mathrm{TM}}$ Plate Certificates, Recognitions and Validations $3 \mathrm{M}^{\mathrm{TM}}$ Petrifilm ${ }^{\mathrm{TM}}$ Plate Certificates. Recognitions and Validations $3 \mathrm{M}$ Microbiology is certified to ISO-9001 for design and manufacturing. Genova; 1997.

AOAC - Association of Official Analytical Chemists. Official method 990.12:aerobic plate count in Foods. Washignton; 1990.

AOAC - Association of Official Analytical Chemists. Official methods of analysis international microbiological methods [998.08 - confirmed Escherichia coli counts in poultry, meats and seafood]. Washington; 1991. 
AOAC - Association of Official Analytical Chemists. Official method 991.14 [coliform and Escherichia coli counts in foods]. Washington; 2015.

Belluco S, Barco L, Roccato A, Ricci A. Escherichia coli and Enterobacteriaceae counts on poultry carcasses along the slaughter line:A systematic review and meta-analysis. Food Control 2016;60(4):269-280.

Brashears MM, Chaves BD. The diversity of beef safety: a global reason to strengthen our current systems. Meat Science 2017;132:59-71.

Brasil. Circular no 668, de 19 de setembro de 2006. Diretrizes para preparação de Plano de APPCC (HACCP) para o processo de abate de aves. Ministério da Agricultura, Pecuária e Abastecimento. Brasília, DF, 19 set. 2006

Brasil. Portaria SDA/MAPA n 210/1998, de 10 de novembro. 1998. Regulamento técnico da inspeção tecnológica e higiênico-sanitária de carne de aves. Diário Oficial da União de 26 nov. 1998.

Brasil. Resolução n. 4 de 4 de outubro de 2011. Autoriza o emprego do sistema de lavagem de carcaças no processo de abate de aves. Diário Oficial da União de 06 jun. 2018.

Brizio APDR, Marin G, Schittler L, Prentice C. Visible contamination in broiler carcasses and its relation to the stages of evisceration in poultry slaughter. International Food Research Journal 2015;22(1):59-63.

Chen XI, Bauermeister L, Hill GN, Singh M, Bilgili SF, McKee SR. Efficacy of various antimicrobials on reduction of salmonella and campylobacter and quality attributes of ground chicken obtained from poultry parts treated in a postchill decontamination Tank. Journal of Food Protection 2014;77(11):1882-1888

Evers EG, Pielaat A, Smid JH, Van Duijkeren E, Vennemann FB, Wijnands LM, et al., Comparative exposure assessment of esblproducing Escherichia coli through meat consumption. PLoS One 2017;12(1):e0169589.

Flanders FB, Gillespie JR. Modern livestock and poultry production. Boston: Cengage Learning; 2016

Giombelli A, Hammerschmitt D, Cerutti MF, Chiarini E, Landgraf M, Franco $\mathrm{BD}$ et al., High pressure spray with water shows similar efficiency to trimming in controlling microorganisms on poultry carcasses. Poultry Science 2016;94(10):2589-95.

ISO - International Organization for Standardization. Microbiology of food and animal feeding stuffs:Horizontal method for the detection of Salmonella spp [ISO 6579:2002]. Geneva; 2002.

Isolan LW, Perdoncini G, Todeschini B, Santos Lr, Guahyba AS, Depner R, et al., Sistema de lavagem de carcaças e controle de Salmonella spp. em abatedouros de frangos de corte. Arquivo Brasileiro de Medicina Veterinária e Zootecnia 2019;71(1):252-258.
Jacxsens L, Kirezieva K, Luning PA, Ingelrham J, Diricks H, Uyttendaele $M$. Measuring microbial food safety output and comparing selfchecking systems of food business operators in Belgium. Food Control 2015;49:59-69.

Lehner Y, Reich F, Klein G. Influence of process parameter on Campylobacter spp. counts on poultry meat in a slaughterhouse environment. Current Microbiology 2014;69(3):240-244.

Milios K, Drosinos EH, Zoiopoulos PE. Carcass decontamination methods in slaughterhouses: a review. Journal of the Hellenic Veterinary Medical Society 2014a;65(2):65-78.

Milios K, Drosinos EH, Zoiopoulos PE. Food safety management system validation and verification in meat industry:Carcass sampling methods for microbiological hygiene criteria - A review. Food Control 2014:43:74-81.

Pawar SS, Basavaraj S, Dhansing V, Pandurang KN, Sahebrao KA, Vithal $N A$, et al., Assessing and mitigating the impact of heat stress in poultry. Advances in Animal and Veterinary Sciences 2016;4(6):332-341.

Rodrigues WOP, Garcia RG, Naas IA, Rosa CO da, Caldarelli CE. Cadeia produtiva do frango de corte de mato grosso do sul:uma análise de conduta de mercado. Organizações Rurais \& Agroindustriais 2015;17(1):137-147

SAS. Sas/Access 9.3 interface to people softwar. User's guide. Cary; 2012.

Seliwiorstow T, Baré J, Berkvens D, Van Damme I, Uyttendaele M, Zutter L. Identification of risk factors for Campylobacter contamination levels on broiler carcasses during the slaughter process. International Journal of Food Microbiology 2016;226:26-32.

Silva VP, WERF HM van der, Soares SR, Corson MS. Environmental impacts of French and Brazilian broiler chicken production scenarios:An LCA approach. Journal of Environmental Management 2014;133(2):222231.

Sohaib M, Anjum FM, Arshad MS, Rahman UU. Postharvest intervention technologies for safety enhancement of meat and meat based products;a critical review. Journal of Food Science and Technology 2016;53(1):19-30.

Stefani LM, Backes RG, Faria GA, Biffi CP, Almeida JM, Silva HK, etal., Trimming and washing poultry carcass to reduce microbial contamination: a comparative study. Poultry Science 2014;93(12):3119-3122.

Zweifel C, Althaus D, Stephan R. Effects of slaughter operations on the microbiological contamination of broiler carcasses in three abattoirs Food Control 2015;51:37-42. 